\title{
Superplastic Deformation Mechanisms \\ in Powder Metallurgically Processed \\ Al-5Mg-2.2Mn Alloy
}

\author{
Kenji Higashi ${ }^{\text {¿1 }}$, Yasushi Matsumura ${ }^{\text {i1 }}$

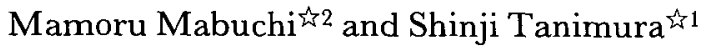 \\ t1 College of Engin, Dept. Mech. Sys. Engin, Uni, of Osaka Prefecture, Sakai 593. \\ National Industrial Research Institute of Nagoya, 1-1 Hirate-cho Kita-ku, Nagoya 462.
}

Received June 14, 1994

The tensile behavior of a powder metallurgically processed $\mathrm{Al}-5 \mathrm{mass} \% \mathrm{Mg}$ $2.2 \mathrm{mass} \% \mathrm{Mn}$ alloy with a fully recrystallized fine grained structure of $3 \mu \mathrm{m}$ in size was characterized at strain rates between $10^{-4}$ and $2 \mathrm{~s}^{-1}$ at temperatures from 748 to $823 \mathrm{~K}$. This alloy exhibited superplasticity at high strain rates around $10^{-2} \mathrm{~s}^{-1}$. A maximum elongation of $570 \%$ was obtained at a constant strain rate of $6 \times 10^{-3} \mathrm{~s}^{-1}$ at $823 \mathrm{~K}$. An analysis of the threshold stress indicated that the true stress exponent is 2 for all testing temperatures and the true activation energy for superplastic flow is equal to that for lattice diffusion in aluminum. It is postulated that superplastic flow in the $\mathrm{P} / \mathrm{M}$ Al-Mg-Mn alloy is controlled by a grain boundary sliding mechanism accommodated by dislocation climb or glide controlled by lattice diffusion.

\section{Introduction}

It was recently reported that very fine grained aluminum alloys were obtained by a combination of powder metallurgy and/or advanced processing methods, including mechanical alloying ${ }^{1-6)}$, consolidation from amorphous powders ${ }^{7-9)}$ or nanocrystalline powders ${ }^{10)}$ and physical vapor deposition ${ }^{11}$. A group of the powder metallurgically processed $\mathrm{Al}-\mathrm{Cu}, \mathrm{Al}-\mathrm{Mg}$ and $\mathrm{Al}-\mathrm{Zn}-\mathrm{Mg}$ system alloys with a large amount of $\mathrm{Cr}, \mathrm{Mn}$ or $\mathrm{Zr}$ has been made to a fine grained super-plastic structure of less than $5 \mu \mathrm{m}$ by optimum powder metallurgical processings. These P/M alloys showed large elongations of more than $500 \%$ at high strain rates over about $10^{-2} \mathrm{~s}^{-1}$ and consist of two groups, statically recrystallized and dynamically recrystallized alloys due to the difference of recrystallization behavior ${ }^{12,13)}$. The former are $\mathrm{P} / \mathrm{M}$ aluminum alloys with $\mathrm{Cr}$ or $\mathrm{Mn}$, and the latter are other $\mathrm{P} / \mathrm{M}$ aluminum alloys including $\mathrm{Zr}$.

In this paper, the deformation mechanisms of high strain rate superplasticity in a $\mathrm{P} / \mathrm{M}$ Al-5mass\%Mg-2.2mass\% $\mathrm{Mn}$ alloy with a fully recrystallized fine grained structure of about $3 \mu \mathrm{m}$ are addressed from the experimental data characterized at various strain rates and temperatures.

\section{Experimental procedures}

The chemical compositions of powder metallurgically processed aluminum alloys used in the present work are given as 
Al-5mass\%Mg-2.2mass\%Mn. A P/M aluminum alloy was produced in the form of extruded bars by Technical Research Laboratories of Sumitomo Light Metal Industries Ltd. then processed by superplastic thermo-mechanical treatment into thin rolled sheet form at our laboratory. Tensile samples with $5 \mathrm{~mm}$ gauge length and $4 \mathrm{~mm}$ width were machined from these rolled sheets, which gauge length was parallel to the rolling direction. Tensile tests were carried out in air at temperatures between 748 and $823 \mathrm{~K}$ and in a wide strain rate range from $10^{-4}$ and $2 \mathrm{~s}^{-1}$ on the tensile testing machines controlled by computers that allowed the true constant strain rate tests. The flow stresses for each sample at given strain rates and temperatures were determined from the fixed true strain of 0.1 .

\section{Results and analysis}

The elongation of the P/M Al-Mg-Mn alloy at testing temperatures between 748 and $823 \mathrm{~K}$ is shown in the bottom part of Fig. 1 as a function of strain rate. An optimum superplastic strain rate range for large elongations more than $300 \%$ at each temperature is nearly $10^{-2} \mathrm{~s}^{-1}$, and the maximum elongation values seem to increase with increasing temperature. A maximum elongation of $570 \%$ was obtained at a relatively high strain rate of $6 \times 10^{-3} \mathrm{~s}^{-1}$ at $823 \mathrm{~K}$.

The flow stress of the P/M Al-Mg-Mn alloy at various temperatures as a function of strain rate is shown in the top part of Fig. 1. The flow stress increased with increasing strain rate, there are typical curves of sigmoid have been observed for superplastic materials. In the low strain rate regime, the low strain rate sensitivity indicates an apparent threshold stress. In the P/M Al-Mg-Mn alloy with a large amount of $\mathrm{Mn}$, additional mechanisms may be responsible for inclusion of oxides from the aluminum alloys powders and a large amount of fine particles of $\mathrm{Al}_{6} \mathrm{Mn}$ by the powder metallurgical process providing resistance to grain boundary sliding or acting as effective barriers to dislocation motion. In the high strain rate range where superplasticity was obtained, a high strain rate sensitivity of about $0.5(n=2)$ was obtained, with corresponding relatively large elongations.

Superplastic deformation is usually described by an equation for power-law creep of the form ${ }^{14)}$,

$$
\frac{\dot{\varepsilon} k T}{D G b}=A\left(\frac{b}{d}\right)\left(\frac{\sigma}{G}\right)^{n}
$$

where $A$ is a geometrical constant; $\dot{\varepsilon}$ the strain rate; $\sigma$ the stress; $n(1 / m)$ the stress exponent; $k$ Boltzmann's constant; $T$ the absolute temperature; $d$ the grain size; $b$ the Burgers vector; $p$ the grain size exponent; $G$ the temperature-dependent shear modulus and $D=D_{0} \exp (-Q / R T)$ the appropriate diffusivity ( $R$ the gas constant; $D_{0}$ the frequency factor

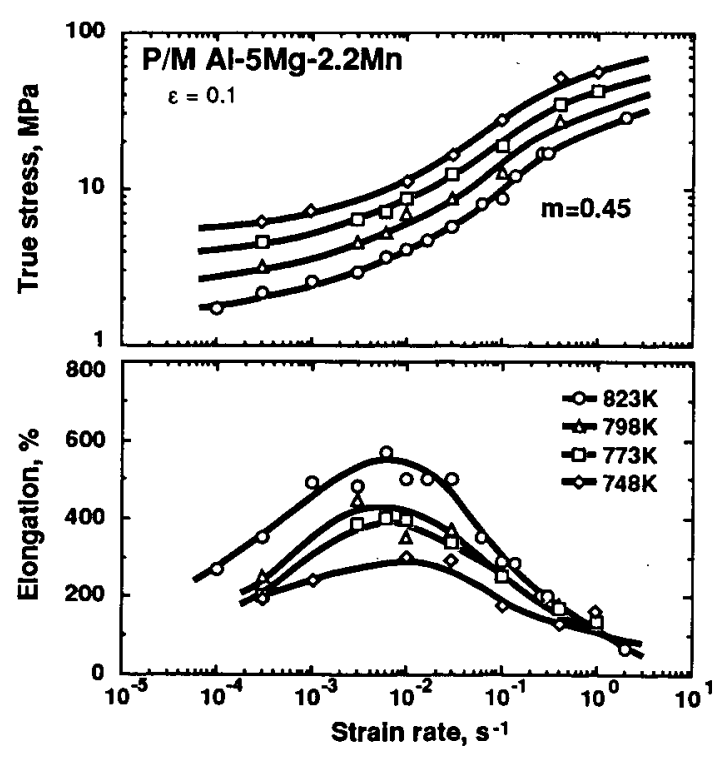

Fig. 1 Elongation and stress of the $\mathrm{P} / \mathrm{M} \mathrm{Al}-\mathrm{Mg}-\mathrm{Mn}$ alloy at temperatures between 748 and $823 \mathrm{~K}$ as a function of strain rate. 
and $Q$ the activation energy of an appropriate diffusion process). In the case where a threshold stress $\sigma_{o}$ is indicated, $\sigma$ is usually replaced by $\left(\sigma-\sigma_{o}\right)$. An apparent temperature-dependent threshold stress can be estimated from the only mechanical data from the superplastic strain rate regime of the top part of Fig. 1 using the approach suggested by Mohamed ${ }^{15}$. Fig. 2 shows a double linear plot of $\sigma$ against $\dot{\varepsilon}^{m}$ for a value $m=0.5$ predicted by the most theoretical model of superplastic deformation. Numeric processing enabled to determine $\sigma_{o}$ values for each testing temperature resulting in the best linear fit of the $\sigma$ vs. $\dot{\varepsilon}^{m}$ dependence. The values 5.15, 3.65, 2.72 and $1.60 \mathrm{MPa}$ for the threshold stress in the case of $m=0.5$ were obtained at temperatures of $748,773,798$ and $823 \mathrm{~K}$ respectively.

The mean value of the grain size $d$ annealed for $1.8 \mathrm{ks}$ at each testing temperature is shown in Table 1, indicating that grain size $d$ increases slightly from 2.3 to $3 \mu \mathrm{m}$ with increasing temperature. Including in Table 1 the threshold stress measured in Fig. 2, and the shear modulus is obtained from dynamic modulus studies on the 5056 (Al-Mg-Mn) alloy ${ }^{16)}$. From the values in grain size, thresh-

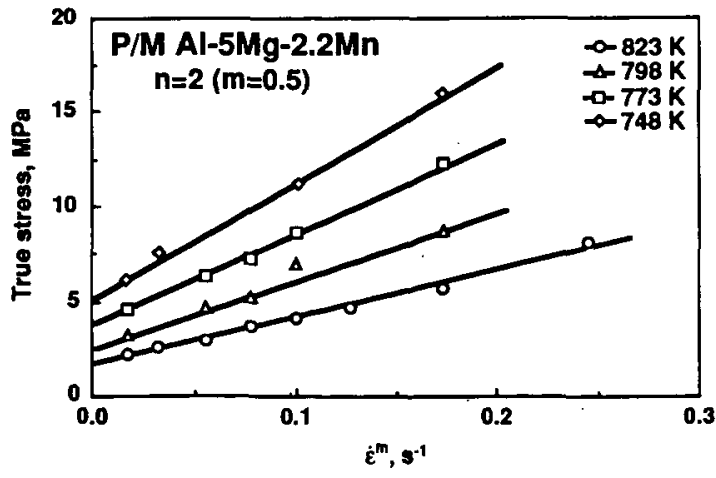

Fig. 2 A double linear plot of $\sigma$ against $\dot{\varepsilon}^{n}$ for a value $m=0.5$ predicted by the most theoretical model of superplastic deformation.
Table 1

The values of grain size, threshold stress and shear modulus.

\begin{tabular}{lcccc}
\hline Temperature (K) & 748 & 773 & 798 & 823 \\
\hline Grain size $(\mu \mathrm{m})$ & 2.30 & 2.51 & 2.67 & 3.00 \\
$\begin{array}{c}\text { Threshold stress } \\
(\mathrm{MPa})\end{array}$ & 5.15 & 3.65 & 2.72 & 1.60 \\
$\begin{array}{c}\text { Shear modulus } \\
(\mathrm{GPa})\end{array}$ & 14.20 & 12.57 & 10.71 & 8.61 \\
\hline
\end{tabular}

old stress and shear modulus shown in Table 1, the $\log \left\{\left(\sigma-\sigma_{0}\right) / G\right\}$ us. $\log \left(\dot{\varepsilon} d^{2}\right)$ dependence could be obtained in a double logarithmic scale, using the value of 2 in grain size exponent $p$ which was reported for the superplastic Al-5Mg-0.5Mn aluminum alloy ${ }^{17}$. From the relationship between $\log \left\{\left(\sigma-\sigma_{0}\right) / G\right\}$ and $\log \left(\dot{\varepsilon} d^{2}\right)$ the true activation energy $Q$ can be evaluated according to eqn.(1). The measured activation energy $Q$ was $142 \mathrm{~kJ} / \mathrm{mol}$, which was the value of the reported activation energy for lattice diffusion in pure aluminum $\left(142 \mathrm{~kJ} / \mathrm{mol}^{18)}\right.$ ).

Thus, it is possible to normalize the

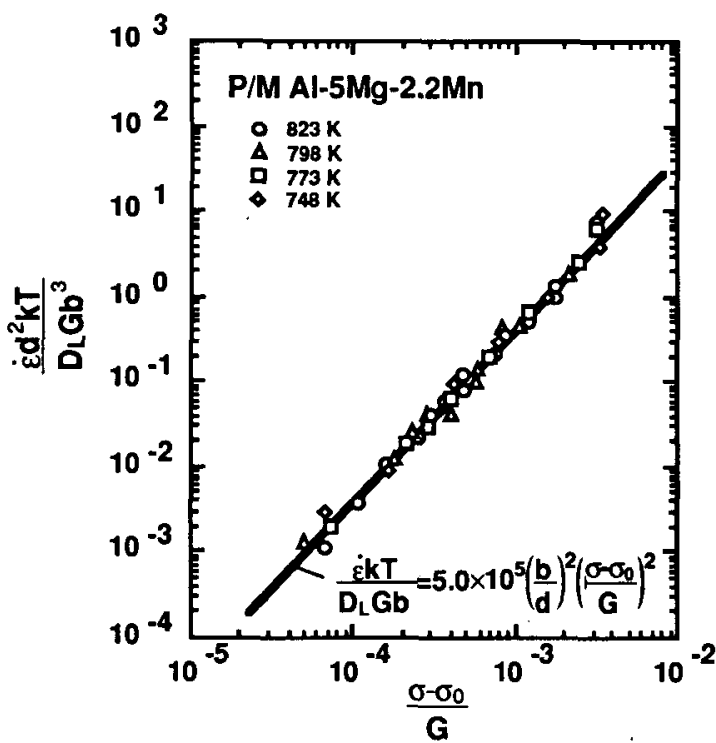

Fig. 3 Diffusion-and grain-size-compensated strain ratevs. modulus-compensated effective stress for the fine grained P/M Al-5Mg-2.2Mn alloy. 
superplastic mechanical data in Fig. 1 by plotting them in the form of eqn.(1). By using the lattice diffusion coefficient $D_{L}$ and the normalized effective stress $\left\{\left(\sigma-\sigma_{0}\right) / G\right\}$, the summary is obtained for testing temperatures as shown in Fig. 3. The geometrical constant value $A$ of the constants $5 \times 10^{5}$ is estimated in the form of eqn.(1), the constitutive equation of the superplastic deformation for the $\mathrm{P} / \mathrm{M} \mathrm{Al}$ $\mathrm{Mg}-\mathrm{Mn}$ alloy is given by

$$
\frac{\dot{\varepsilon} k T}{D_{L} G b}=5.0 \times 10^{5}\left(\frac{b}{d}\right)^{2}\left(\frac{\sigma-\sigma_{0}}{G}\right)^{2}
$$

The result is in very close agreement with the conclusion that superplastic flow in the fine grained $\mathrm{P} / \mathrm{M} \mathrm{Al}-\mathrm{Mg}-\mathrm{Mn}$ alloy is controlled by a grain boundary sliding mechanism accommodated by dislocation climb or glide controlled by lattice diffusion.

\section{Summary}

High strain rate superplasticity was obtained in the powder metallurgically processed $\mathrm{Al}-5 \mathrm{mass} \% \mathrm{Mg}-2.2 \mathrm{mass} \% \mathrm{Mn}$ aluminum alloy. Introducing a threshold stress, shear modulus and grain size into the rate equation, the true values of $n$ and $Q$ established as 2 and $142 \mathrm{~kJ} / \mathrm{mol}$ respectively. It is postulated that superplastic flow in this alloy is controlled by a grain boundary sliding mechanism accommodated by dislocation climb or glide controlled by lattice diffusion.

\section{References}

1) T.G.Nieh, P.S.Gilman and J.Wadsworth, Scripta. Metall.,19(1985)1375.

2) T.R.Bieler, T.G.Nieh, J.Wadsworth and

A.K.Mukherjee, ibid., 22 (1988)81.

3) K.Higashi, T.Okada, T.Mukai and

S.Tanimura, ibid., 25 (1991)2053.

4) K.Higashi, T.Okada, T.Mukai,

S.Tanimura, T.G.Nieh and J.Wadsworth, ibid., 26 (1992)185.

5) K.Higashi, T.Okada, T.Mukai and

S.Tanimura, ibid., 26 (1992)761.

6) K.Higashi, T.Okada, T.Mukai and S.Tanimura, Mater. Sci. Eng., A159 (1992)L1.

7) A.Inoue, K.Kita, K.Ohtera, H.Kimura and T.Masumoto, J.Mater.Sci.Lett., 7 (1988)1287.

8) K.Ohtera, A.Inoue and T.Masumoto, Mater. Sci. Eng., A134 (1991)1212.

9) K.Higashi, T.Mukai, S.Tanimura, A.Inoue, T.Masumoto, K.Kita, K.Ohtera and J.Nagahora, Scripta Metall. Mater., 26 (1992)191.

10) H.Nagahama, K.Ohtera, K.Higashi, A.Inoue and T.Masumoto, Philos. Mag. Lett., 67 (1993)225.

11) R.W.Gardiner and M.C.McConnell, Metals and Materials, 3 (1987)254.

12) K.Higashi, S.Tanimura and T.Ito, MRS Sym. Proc. Vol.196, Pittsburgh, (1990)385.

13) K.Higashi, S.Itsumi, M.Hoshikawa, Y.Matsumura, T.Ito, S.Tanimura and H.Yoshida, Superplasticity in Advanced Materials, The Jap. Society for Research on Superplasticity, Osaka, (1991)575.

14) J.E.Bird,A.K.Mukherjee and J.F.Dorn, "Quantitative Relation Between Properties and Microstructure", ed by D.G.Brandon and A.Rosen, Israel Universities Press, (1969)255.

15) F.A.Mohamed, J. Mat. Sci., 18 (1983)582.

16) Y.Takeuchi, S.Komori,N.Noda and H. Nyuko, J. Thermal Stresses, 2 (1979)233.

17) H.Iwasaki, S.Hayami, K.Higashi and S.Tanimura, Mater. Sci. Forum, 94-96 (1992)759.

18) H.J.Frost and M.F.Ashby, "Deformation Mechanism Maps", Pergamon, Oxford,(1982). 